\author{
خزر \\ نسرين نيكمهر، سهيل ايخدرى" و يريا جليلى

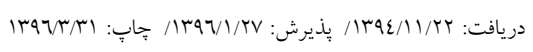 \\ كروه شيلات، يرديس كشاورزى و منابع طبيعى كرج، دانشكدة منابع طبيعى، دانشخاه تهران، كرج، ايران \\ soheil.eagderi@ut.ac.ir :مسئول مكاتبات
}

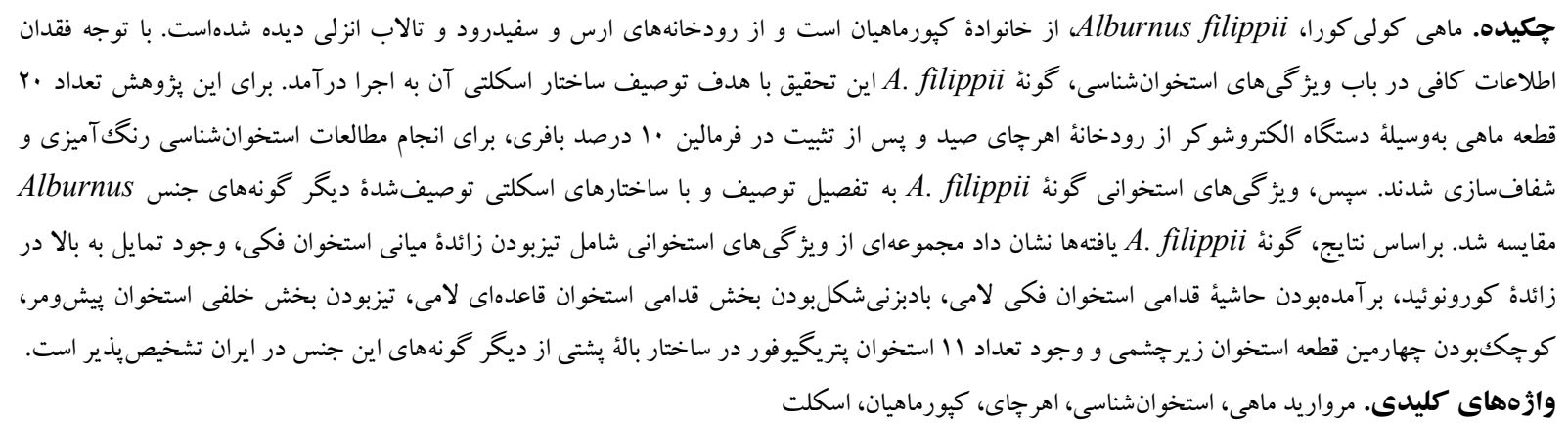

\title{
Skeletal structure of Kura bleak, Alburnus filippii (Kessler, 1877), in South Caspian Sea basin
}

Nasrin Nikmehr, Soheil Eagderi* \& Pariya Jalili

Received 11.02.2016/ Accepted 16.04.2017 / Published 21.06.2017

Department of Fisheries, Faculty of Natural Resources, University of Tehran, Karaj, Iran

*Correspondent author: soheil.eagderi@ut.ac.ir

Abstract. Kura bleak, Alburnus filippii, a member of the family Cyprinidae, is found in the rivers of Aras and Sefidrud, and the Anzali lagoon of Iran. The current study was conducted to provide a detailed osteological description of this species since there was not adequate information in this regard. In order to attain this goal, 20 specimens were collected from the Ahar Chay River by electrofishing device, and fixed in 10\% buffered formalin. The specimens were cleared, stained with alizarin red $\mathrm{S}$ and alcian blue for osteological examination and a detailed description of its skeletal structure was provided. The results showed that this species can be distinguished from other members of this genus in Iran by a combination of osteological characters, including having pointed process of the maxillae, dorsal tilting of the coronoid process, protruding of the anterior margin of the hyomandibular, fan-shaped anterior part of the basihyal, pointed end of the pre-vomer posteriorly, small fourth infraorbital and 11 pterygiophors in the dorsal fin.

Keywords. Kura bleak, osteology, Ahar Chay, Cyprinidae, skeleton

A. zagrosensis وروميه، (A. caeruleus (Heckel, 1843)

A. chalcoides از حوضئ دجله، (Coad, 2009)

ز A. filippii (Kessler, 1877)و (Güldenstaedt, 1772)

حوضة درياى خزر، A. hohenackeri (Kessler, 1877)

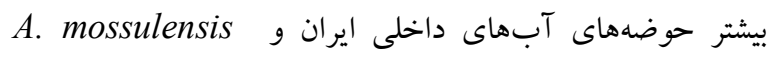
(Heckel, 1843)

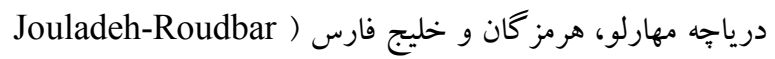

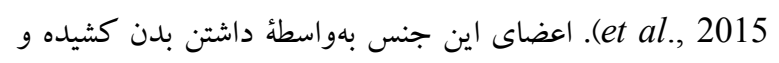

مقدمه

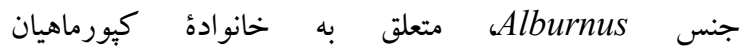

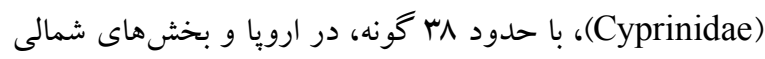
جنوب غرب آسيا يافت مىشود ) Kottelat \& Freyhof, 2007 جنس در ايران يافت شده كه عبارتاند از - Alburnus ami rkabiri (Mousavi-Sabet et al., 2015) نمكك، (A. atropatenae (Berg, 1925) از حوضء درياجٌ 
بسيارى از ماهى ها بهمثابهٔ صفات، مقبول متخصصان ردهبندى قرار كرفته است (Coad, 2015). شناخت ساختار اسكلتى، علاوهبر كمكك به مطالعات فسيل شناسى ماهيان، در بررسىهاى زيستشناسى آنها ازجمله تغذيه، تنفس و شنا نيز داراى اهميت است. بنابراين، براى شناخت زيست يك كونه، شناخت كامل ساختار استخوانى آن ضرورى بهنظر مىرسد (Helfman, 2009). بهويزه، ويز كى هاى استخوانشناسى يكك ابزار مفيد براى مطالعه طبقهبندى و تبارشناسى روابط بين ماهيان است ( Nasri, 2013; Eagderi et al., 2010 a, b است به روشنشدن وضعيت اين گروه از ماهيان كمك كند. اخيراً، مطالعاتى درباب ساختار استخوان برخى گونههاى متعلق به جنس Alburnus صورت گرفتهاست (Jalili et al., 2015a, b) اما در مورد ويثز گیىاى اسكلتى گونه A. filippii اطلاعاتى در دسترس نيست. باتوجه به اهميت نقش استخوان در ردهبندى و آرايهشناسى ماهيان و همجِنين با توجه فقدان اطلاعات كافى در باره ويز كىهاى استخوانى گونهُ ماهى كولى كورا، اين تحقيق بهمنظور توصيف ساختار اسكلتى كامل آن به اجرا درآمد. نتايج اين يُزوهش مى تواند يايهاى براى مطالعات آتى آرايهشناسى اين جنس براساس صفات معتبر استخوانى باشد.

\section{مواد و روشها}

براى اين تحقيق ·r عدد ماهى كولى كورا (شكل I) از رودخانه اهرجاى (شاخهُ فرعى رودخانهُ ارس) توسط دستگاه الكتروشوكر نمونهبردارى شد. نمونه ها، يس از بيهوشى در محلول كل ميخكك، در فرمالين •ا درصد بافرى تثبيت شدند. تعداد با قطعه ماهى بهمنظور مطالعه استخوانشناسى انتخاب و براساس روش اصلاحشده بهوسيلة آلسيانبلو و آليزارين (Taylor \& Van Dyke, 1985) رد شفافسازى و رنگكَ آميزى شدند. ساختارهاى استخوانى توسط دستكاه اسكنر Epson v600 كه به يكك حمام كليسيرين مجهز

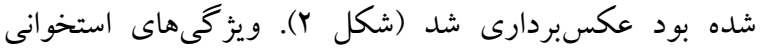
Leica (MS5) نمونها نيز با يكك دستگاه استريو ميكروسكوٍ بررسى و توصيف شد. ترسيم و نام گذارى تصاوير بهدست آمده در نرمافزار CorelDraw و نام گذارى قطعات استخوانى براساس Rojo
فشرده از طرفين، اندازهُ كوجّك تا متوسط، دهان انتهايى و فاقد سبيكك، فلسهايى با اندازه متوسط، دندان حلقى دو رديفى با

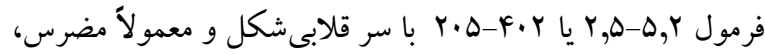
باله يشتى كوتاه بدون شعاع ضخيم، باله مخرجى بلند، يكك كيل

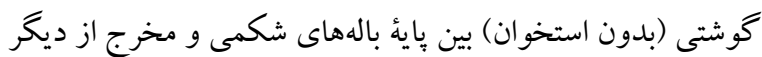
كيورماهيان شناسايى (Coad, 2015) مىشود. Alburnus filippii رودخانهاى ارس، سفيدرود و تالاب انزلى گزارش شدهاست Abbasi et al., 1999; Kiabi et al., 1999; Abdoli \& )

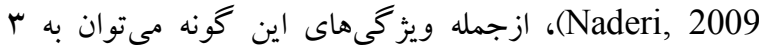
شعاع غيرمنشعب و V شعاع منشعب در باله يشتى، لr M شعاع غير منشعب و r|-9 شعاع منشعب در بالله مخرجى، 19-Y| شعاع

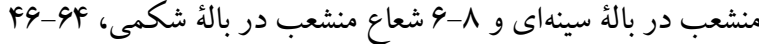
فلس در خط جانبى (فلسهاى بخش قدامى موجدار است و فلس هاى بخش شكمى بيضى شكل است)، كيل شكمى برهنه يا فلس -

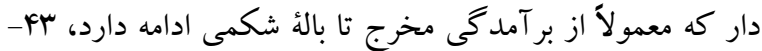
אب ستون مهره و كيسٔ شناى گرد اشاره كرد (Coad, 2015). جنس Alburnus ازنظر آرايهشناختى بيجيده است و حتى احتمال يار افيلتيكبودن اعضاى آن مطرح است (Esmaeili, 2013). بهعلاوه، اين جنس بههمراه جنسهاى Capoeta، Barbus و Squalius كشور ايران دارد و احتمالاً داراى تعدادى گونهُ ناشناخته نيز هست. بنابراين، وضعيت آرايهشناسى آنها نيازمند بازنكرى است

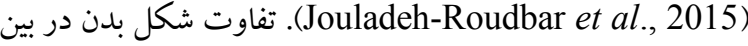
جمعيتهاى اعضاى اين گونه بهواسطة انعطافيذيرى ريختى، اساسىترين گام در روند شكل گيرى گونه هاى جديد مطرح شدهاست (Mohadasi et al., 2013) و بههميندليل مطالعات متعددى كه تاكنون براى تعيين وضعيت آرايهشناسى اعضاى متعلق به اين جنس Alburnus كه بيشتر براساس ويز گیىهاى ريختشناسى ظاهرى و ريختسنجى است، نتوانسته است مشكل وضعيت بيجيده آرايهشناسى اعضاى اين جنس را برطرف كند، بنابراين، بهنظر مىرسد كه در اين مسير استفاده از صفات غير ريختى مىتواند راهكار بهترى فراهم آورد. اخيراً، ويز گیىهاى استخوانشناسى، دركنار مطالعات ملكولى در مطالعهُ ردهبندى 


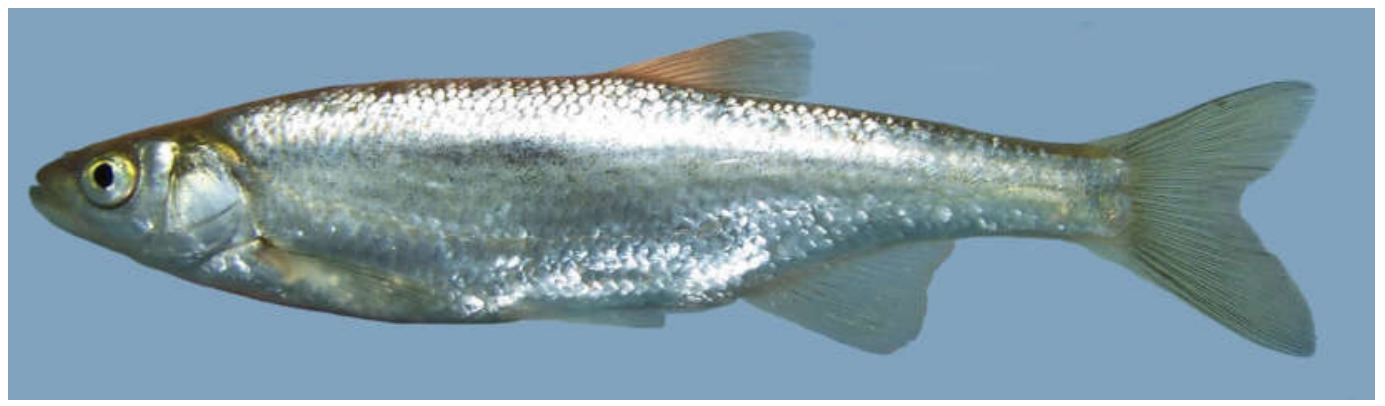

Alburnus filippii شكل 1- نماى جانبى گونئ

Fig. 1. Lateral view of Alburnus filippii

خلفى استخوان حدقهاى بروانهاى قرار دارد و در بخش شكمى

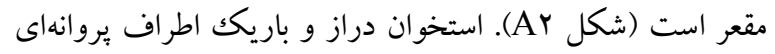

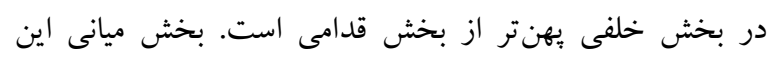

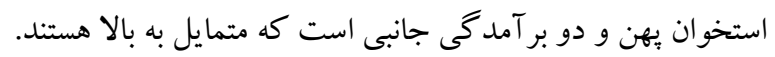

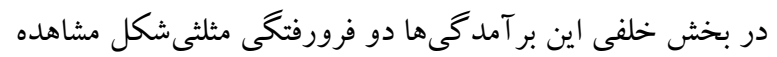

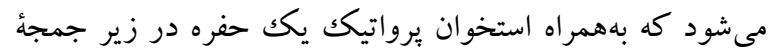

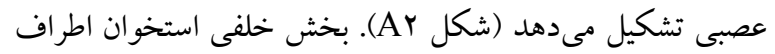

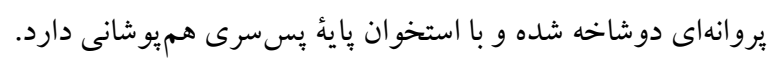

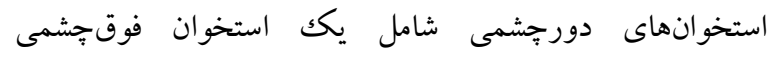
(Infraorbital) و جهار استخوان زيرجشمى (Supraorbital)

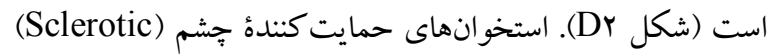

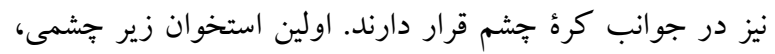

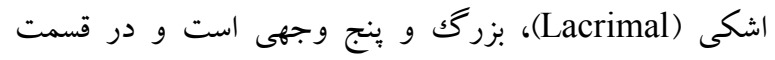

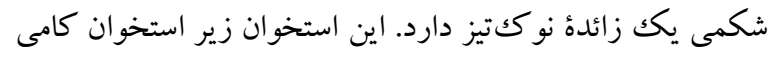
واقع شدهاست. ناحئ شنوايى (Otic) شامل پينج قطعه استخوان

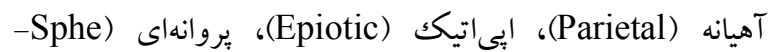

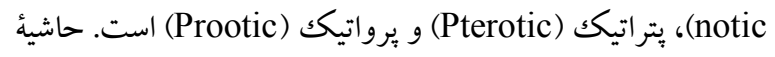
جانبى استخوان آهيانه فروفتخى هاى نامنظمى دارد كه به استخوان-

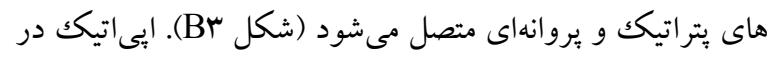

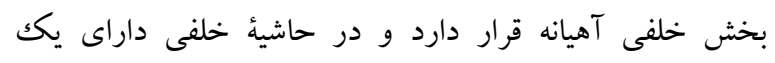
برآمدكى مثلثى شكل است. استخوان بروانهاى در حاشيئ زيرين بخش خلفى بيشانى واقع شدهاست و بر آمدكى قدامى جانبى آن

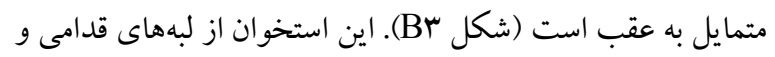
شكمى بهترتيب به استخوانهاى بالى يروانهاى و يرواتيك اتصال

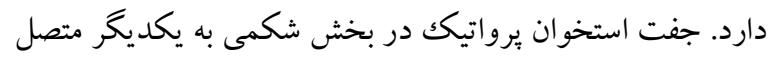

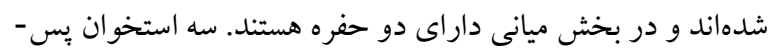

\section{نتايج} نتايج نشان داد كه جمجمة عصبى (Neurocranium) در بخش خلفى بهن است و در بخش ميانى و قدامى كمى باريك مىشود.

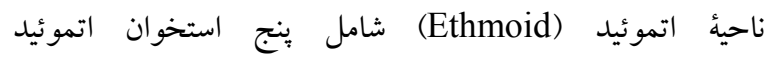
فوقانى(Supra-ethmoid)، اتموئيد جانبى (Lateral ethmoid)، ومر (Vomer)، كيناتموئيد (Kin-ethmoid) و ويشاتموئيد (Pre-ethmoid)

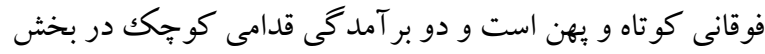

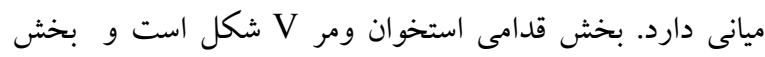

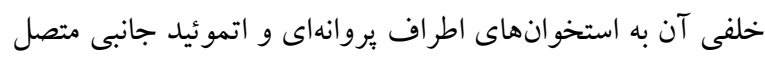

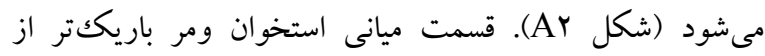

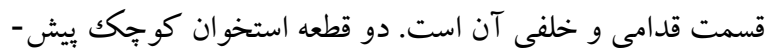
اتموئيد در لبهُ قدامى-جانبى اين استخوان واقع شده است. اتموئيد جانبى در حاشئ خلفى مقعر است و در بخش شكمى مسطح مئشود. اين استخوان ديواره قدامى حدقهُ جشم را تشكيل مىدهد.

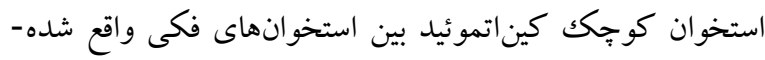
است (شكل Ar). ناحية بينايى (Orbital) شامل استخوانهاى

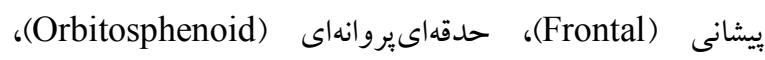

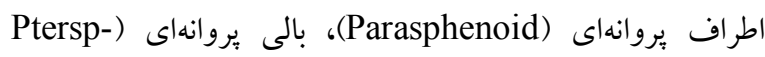

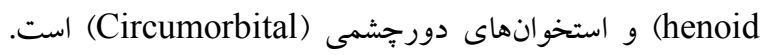

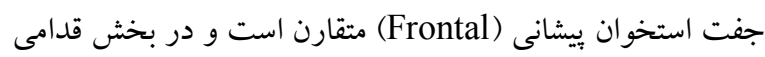
باريك و در بخش خلفى بهن مىشود. اين استخوان در محل

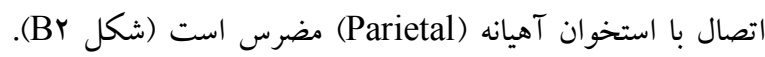

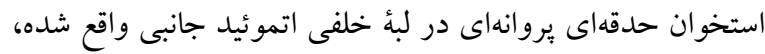

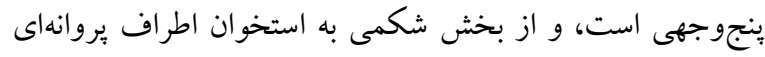

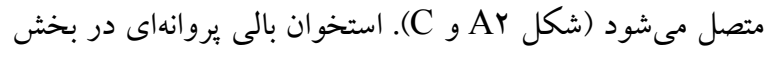


وجود دارد (شكل Br). در لبهُ شكمى-خلفى استخوان مفصلى، استخوان كوجّك و مثلثىشكل رتروآرتيكولار واقع شدهاست.

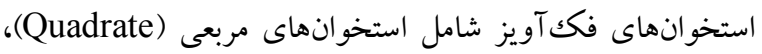

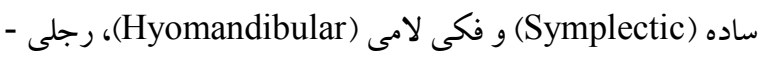
ششتى (Metaptrygoid)، رجلى خارجى (Ectoptrygoid)،

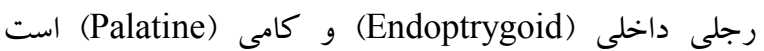

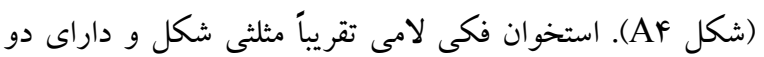

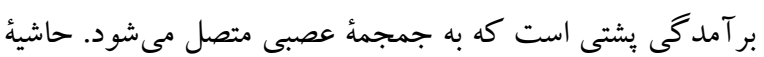

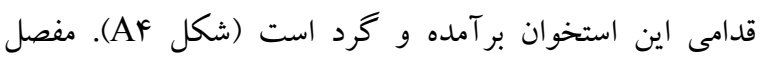
سريوش آبششى (Operclar condyle) توسعه يافته و گرد است استخ

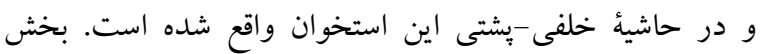
شكمى فكى لامى با استخوان بين لامى مفصل مىشود. استخوان

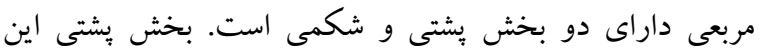

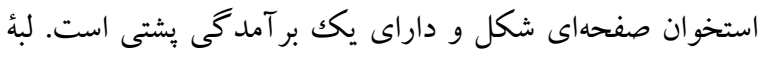

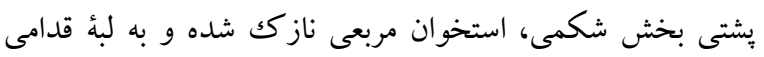
استخوان ميان سريوش آبششى (Interopercle) متصل مىشود. در بخش خلفى استخوان مربعى، استخوان ساده واقع شده كه دراز

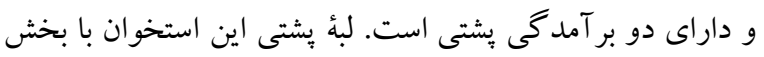

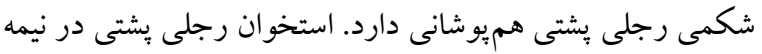
شكمى نيمدايرهاى شكل است و در نيمه يشتى مثلثى شكل مى -

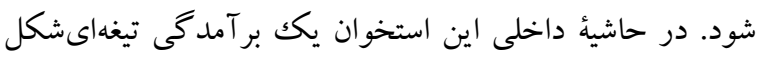
مورب وجود دارد. استخوان رجلىداخلى حاشئ شكمى كاسٔ جشم را تشكيل مىدهد. اين استخوان در قسمت بشتى استخوان رجلى خارجى واقع شدهاست. حاشئ خلفى استخوان رجلى خارجى با حاشئ قدامى استخوان مربعى هميوشانى دارد. رجلى سلى

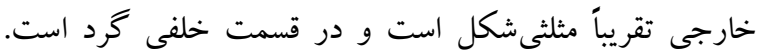

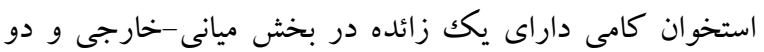

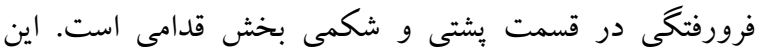
استخوان در بخش خلفى از طريق رجلى خارجى به مجموعة فككآويز و در بخش قدامى به بخش قدامى جمجمة عصبى متصل مى-

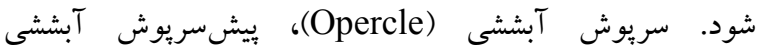
(Preopercle) سريوش آبششى (Interopercle) مجموعة استخوانهاى سريوش آبششى را تشكيل مىدهند (شكل BF). سريوش آبششى در بخش البش
سرى فوقانى (Supraoccipital)، بِسرى خارجى (-) Exoc-

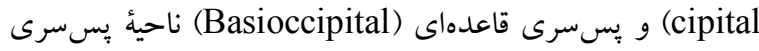

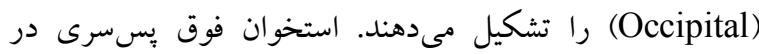
بخش قدامى بهن تر از بخش خلفى و داراى يكك ستيغ (U) Supraoccipital crest است (شكل Br و C) اين استخوان در بخش استش

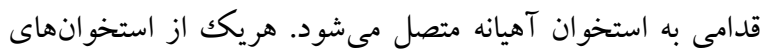

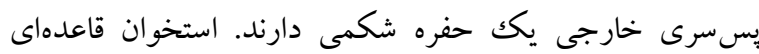
پِس سرى در بخش خلفى داراى زائدة حلقى خلفى است كه در

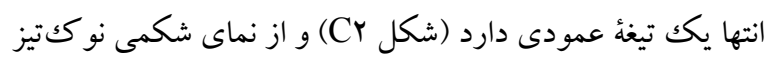

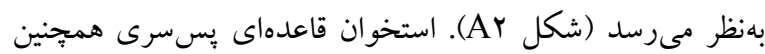

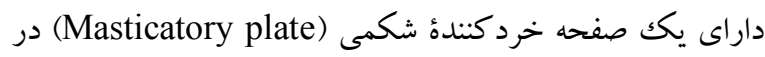

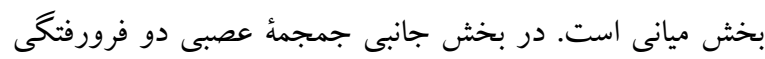
مفصلى براى اتصال به استخوان فكى لامى (Hyomandibular)

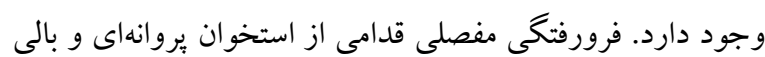

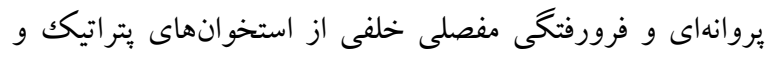

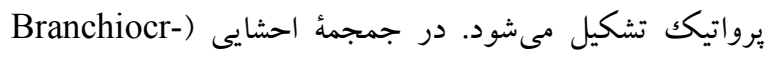

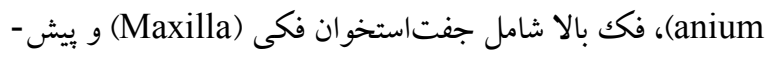

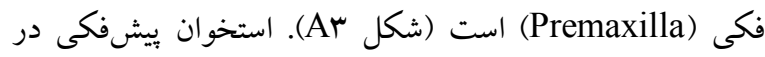
بخش قدامى و ميانى بهن، و در بخش خلفى باريك و و كمى روبه

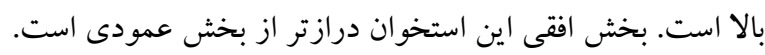

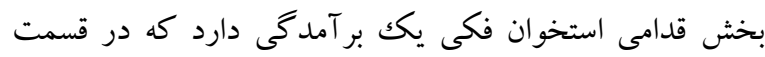

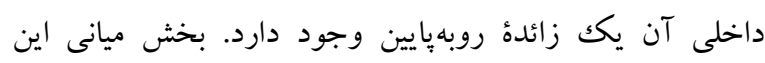

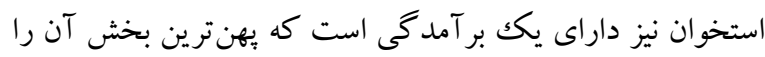
به خود اختصاص مىدهد، اين استخوان در قسمت خلفى باريك و و سيس بهن است.

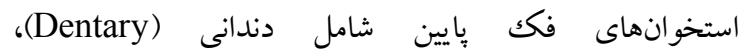

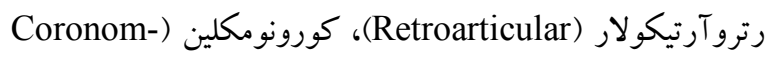

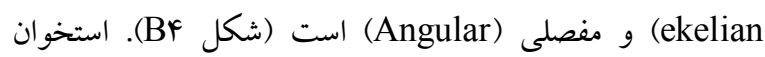
دندانى در بخش قدامى باريكك و متمايل به داخل است. بخش و التش

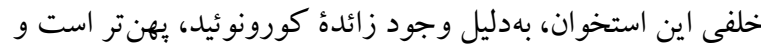
در قسمت ميانى با استخوان مفصلى هميوشانى دارد. بخش ميانى

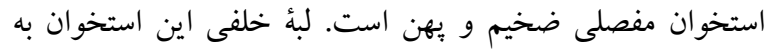
استخوان مربعى (Quadrate) مفصل مىشود. يك قطعه استخوان

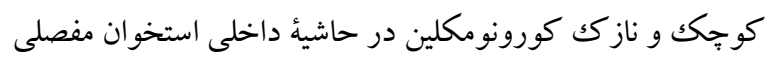



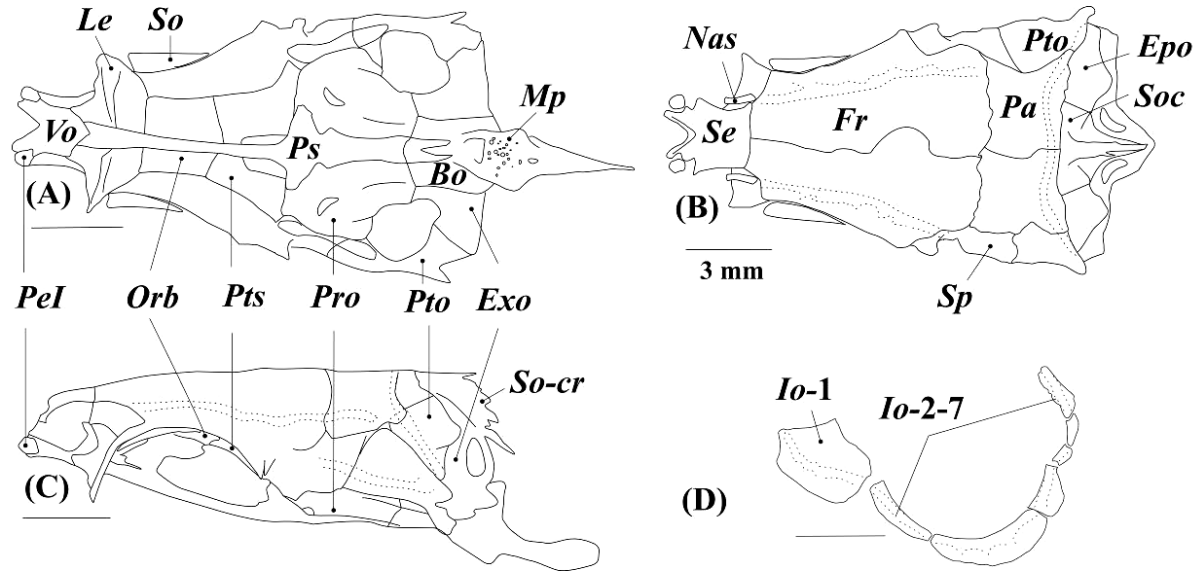

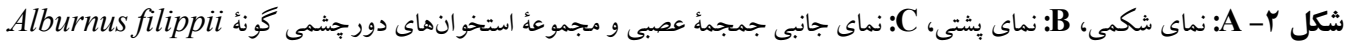

Fig. 2. A: Ventral, B: dorsal and C: lateral views of neurocranium, and circumorbital bones in Alburnus filippii. Abbreviations: Bo: basioccipital; Epo: epiotic; Exo: exoccipita; Fr: frontal; Io: Infraorbital element; Le: lateral ethmoid; Mp: ventral masticatory plate; Nas: nasal; Orb: orbitosphenoid; Pa: parietal; PeI: preethmoid I; Pro: prootic; pr-Pp: posterior pharyngeal process; Ps: parasphenoid; Pto: pterotic; Pts: pterosphenoi; Se: supraethmoid-ethmoid; Soc: supraoccipital; So-cr; supraoccipital crest; Spo: sphenotic; Vo: vomer.

(A)

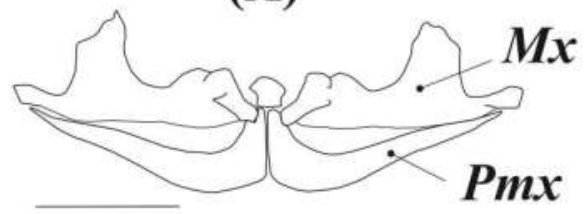

شكل ب - مجموعة استخوانهاى A: فك بالا و B: فكك پيايين گونه Alburnus filippii
(B)

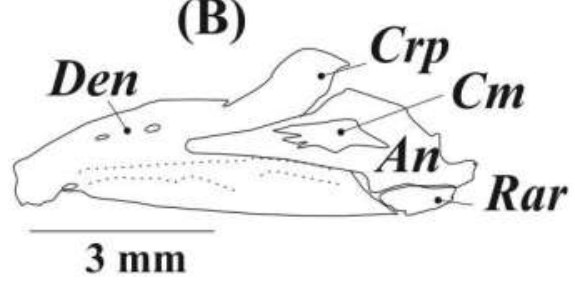

$3 \mathrm{~mm}$

Fig. 3. A: Upper and lower B: jaws of Alburnus filippii.

Abbreviations: An: angular; Crp: coronoid process; Cm: coronomekelian; Den: dentary; Mx: maxillae; Pmx: premaxillae; Rar: retroarticulare.
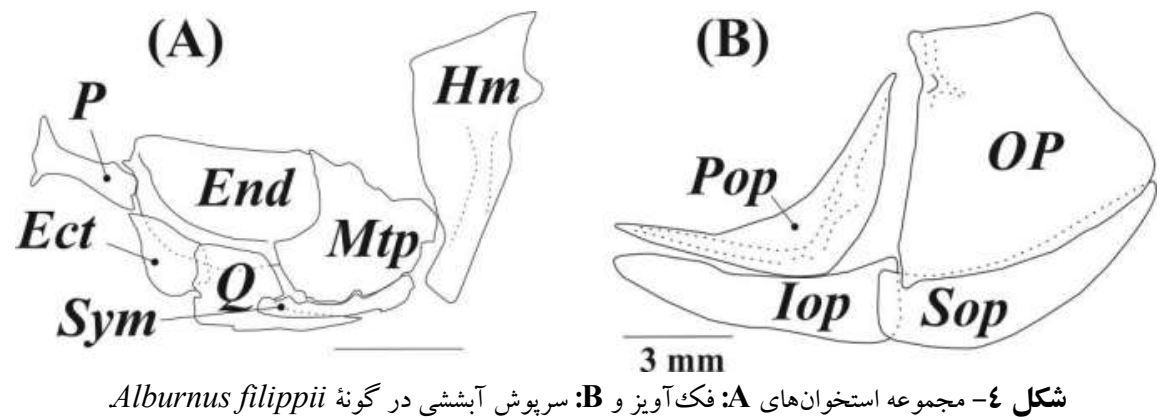

شكل ع- مجموعه استخوانهاى A: فكك آويز و B: سريوش آبششى در گونهُ Alburnus filippii

Fig. 4. A: Suspensorium and B: opercular series of Alburnus filippii.

Abbreviations: Ect: ectopterygoid; End: endopterygoid; Hm: hyomandibulare; Iop: interopercle; Mtp: metapterygoid; Op: opercle; P: palatine; Pop: praeopercle; Q: quadrate; Sop: subopercle; Sym: symplecic. 
- است (شكل B Bibranchial

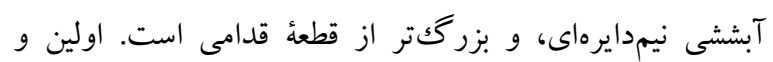

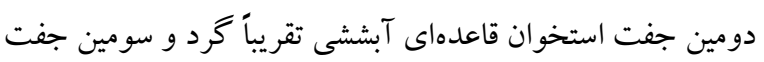

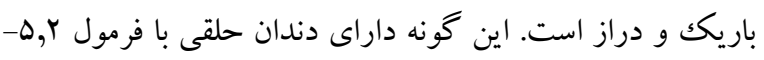
ه, r, است. كمربند سينهاى (Pectoral girdle) شامل استخوان-

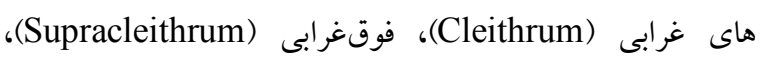

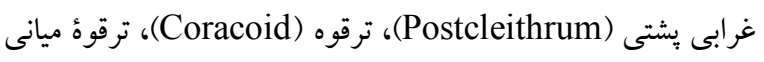
(Mesocoracoid)

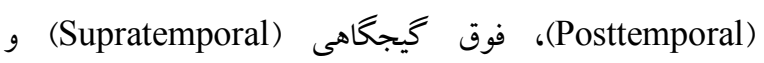

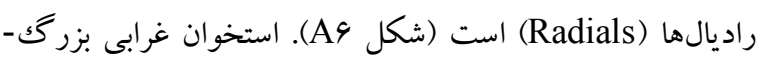

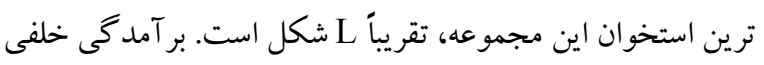

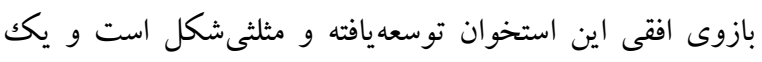

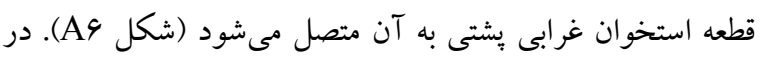

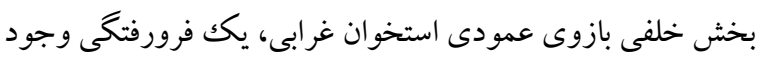
دارد كه استخوان فوقغرابى در آن جاى مى گيرد. فوق غرابى تيغه -

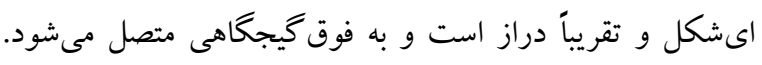

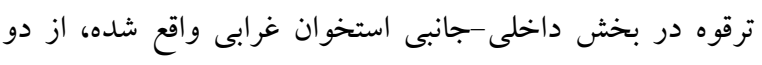
بخش قدامى و خلفى به اين استخوان متصل، و در بخش ميانى فاقد إند

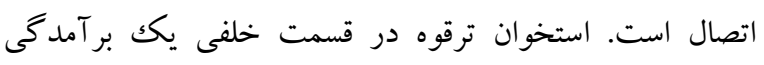

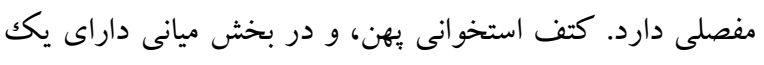

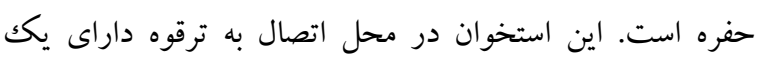

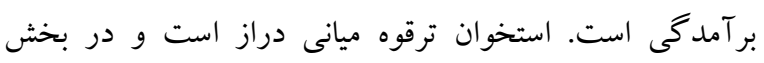

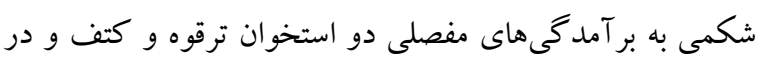

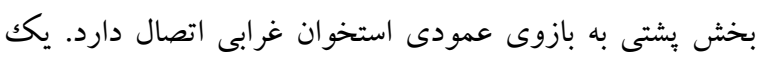

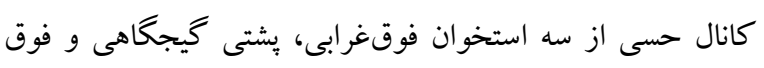

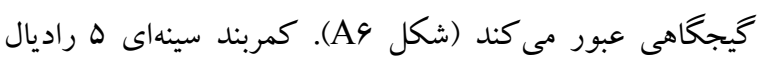

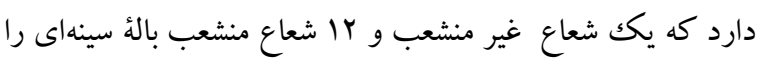
حمايت مى كند. كمربند لكنى (Pelvic girdle)، شامل جفت استخوانهاى

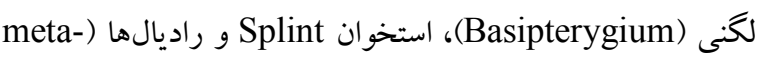
(Bterygium, Radials در بخش خلفى يهن است و در بخش قدامى (Basipterygium) دوشاخه مىشود، فاصله بين اين دوشاخه زياد بود و تقريباً نيم دايرهاىشكل است.
قدامى صاف و در حاشية خلفى مقعر است. در لبهُ قدامى-يشتى

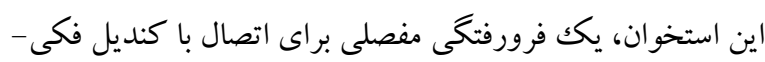

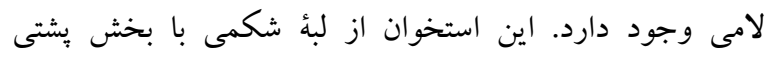

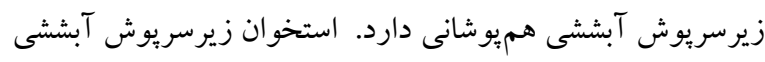

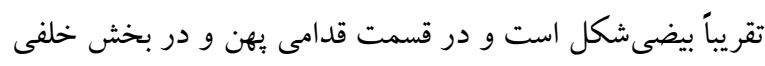

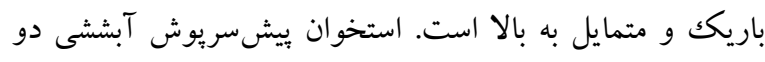

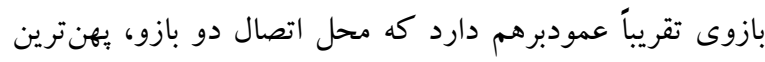

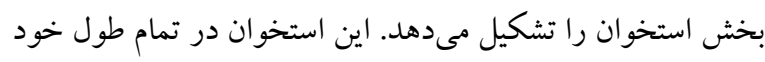

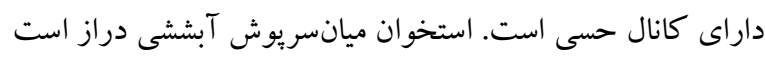

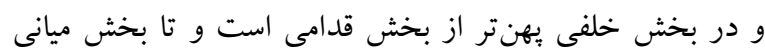

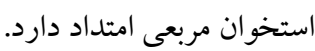
مجموعة كمانى لامى (Hyoid arch) شامل استخوانهاى منفرد

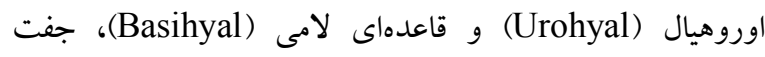

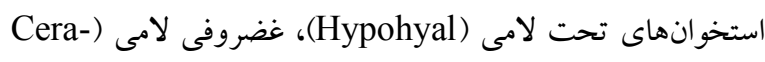

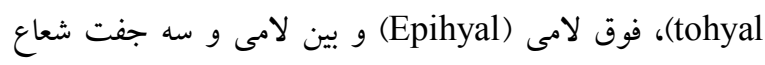

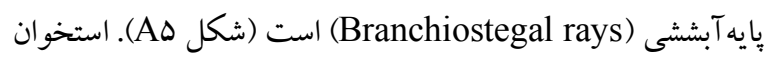
قاعدهاى لامى استخوانى دراز و در بخش قدامى بهن تر از بخش إنش

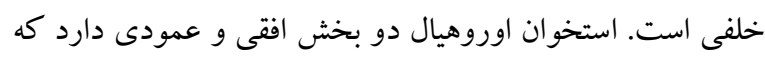
بخش افقى در قسمت قدامى باريك و دوشاخه است و در قسمت

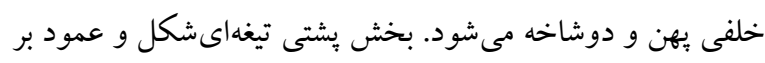

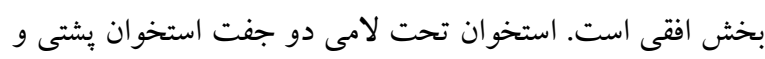

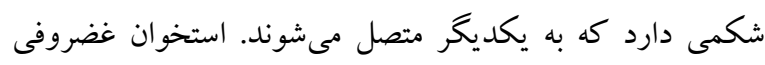

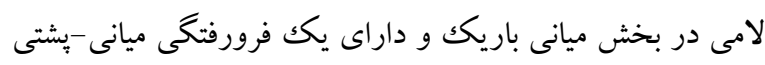

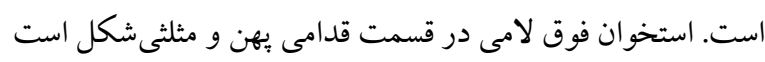

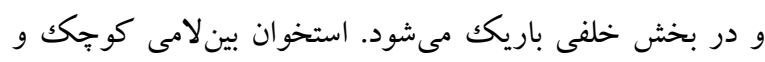
كرد است و در بخش خلفى -يشتى فوق لامى واقع شدهاست.

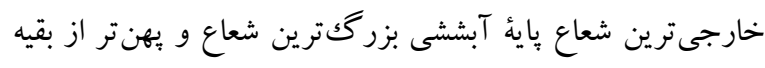

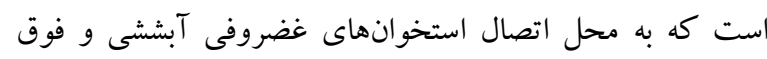

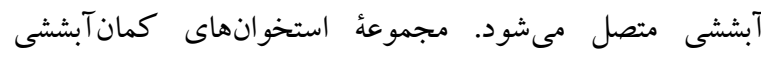
شامل ينججفت استخوان غضروفى (Branchial apparatus)

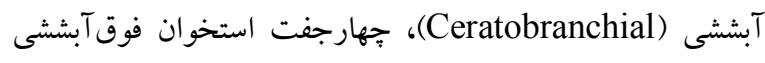
Hypobr-) (Epibranchial) Inphraph-) (anchial Ba- (aryngobranchial 


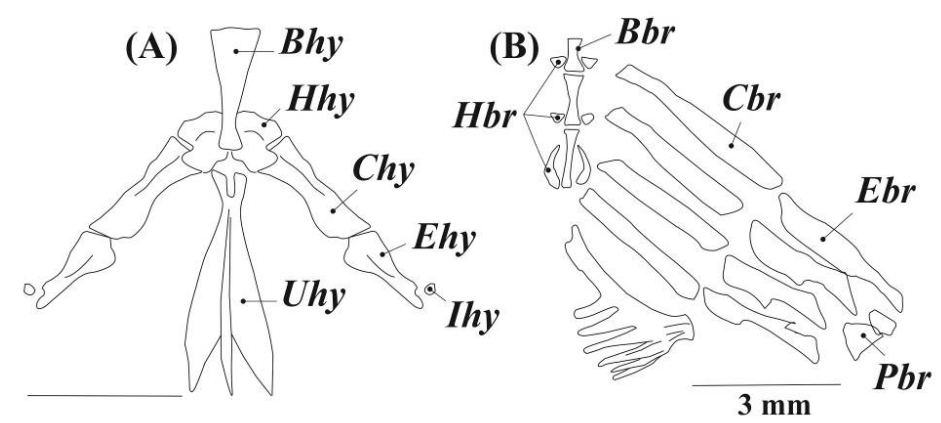

شكل 0- مجموعة استخوانهاى Alburnus filippii كمان لامى و B: كمان آبششى در گونئ.

Fig. 5. A: Hyoid arch B: and branchial apparatus in Alburnus filippii.

Abbreviations: Bhy: basihyal; Chy: ceratohyale;Epy: epihyal; Hhy: dorsal and ventral hypohyal; Ihy: interhyal; Uhy: urohyal; Bbr: basibranchial; Cbr: ceratobranchial; Ebr: epibranchial; Hbr: hypobranchial; Pbr: inphrapharyngobranchial.
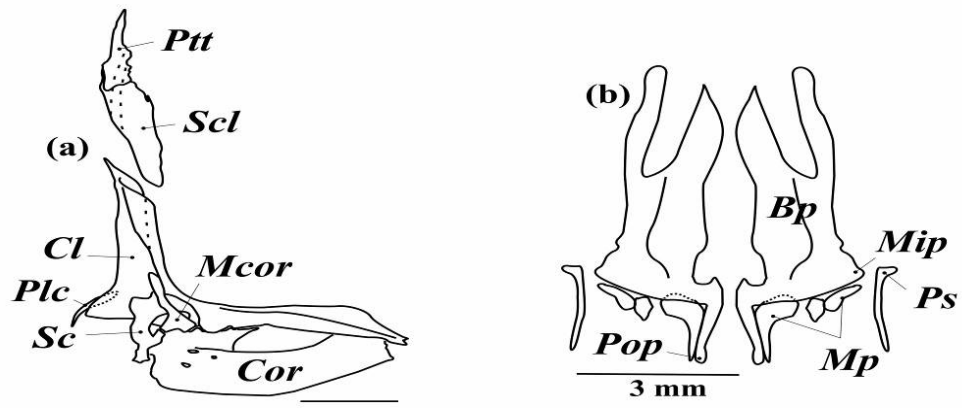

شكل 7- استخوانهاى A: كمربند سينهاى و B: كمربند لكنى در گونه Alburnus filippii

Fig. 6. A: Pectoral and B: pelvic girdles in Alburnus filippii.

Abbreviations: Bp: basipterygium; $\mathrm{Cl}$ : cleitherum; Cor: coracoid; Ps: pelvic splint; Mcor: mesocoracoid; Mip: mid lateral process of basipterygium; Mp: meta-pterygium (Radials); Plc: postcleithrum; PoP: posterior process of basipterygium; Ptt: posttemporal; Sc: scapula; Scl: supracleithrum.

هاى جانبى مهرهُ سوم وجود ندارد و به Tripus تبديل شده است.

دندهاى شكمى مهرة جهارم طويل است و بهسمت يايين بدن

متمايل است. ناحيه جمجمهاى (Cranial) داراى •r جسم مهره و

ناحية دمى (Caudal) داراى \1 جسم مهره است (شكل ^).

زائدهُ زايگايوفيز، شعاع خونى و عصبى مهرههاى شكمى و سينهاى

بلندتر از مهرههاى دمى است. بالهٔ منفرد يشتى داراى سه شعاع

غيرمنشب، ده شعاع منشعب، يازده سرى استخوان يتريخيوفور

(Pterygiophor)

جهارده شروع مىشود. اولين استخوان يتريخيوفور بزرگك است و

دو شعاع غيرمنشعب بالهُ يشتى را حمايت مى كند. استخوان ديستال

در ديخر يتريخيوفورها بهصورت جفت است (شكل A^). بالهٔ

مخرجى نيز داراى سه شعاع غير منشعب و هشت تا نه شعاع منشعب
در حاشئ جانبى-داخلى اين استخوان، يك فرورفتكى و در حاشئ جانبى-خارجى آن يكك برآمدگى مشاهده مىشود (شكل B4). كمربند لكنى داراى سه جفت راديال است، راديال ميانى كوجّكتر از بقيه است و داخلى ترين راديال تقريباً L شكل و منفرد است. جفت استخوان Splint در بخش خارجى اولين شعاع غيرمنشعب باله شكمى واقع شده است كه باريك و طويل است. اين باله داراى يكك شعاع غيرمنشعب و ^ شعاع منشعب است. اسكلت محورى (Axial skeleton) اين گونه در نمونههاى تحت بررسى NM جسم مهره (شكل V) داشت كه مهره اول تا جهارم بههمراه استخوانجههاى Intercalarium ،Scaphium ،Tripus ، و Claustrum جانبى دومين جسم مهره به سمت خلفى بدن قرار گرفتهاند دنده- 


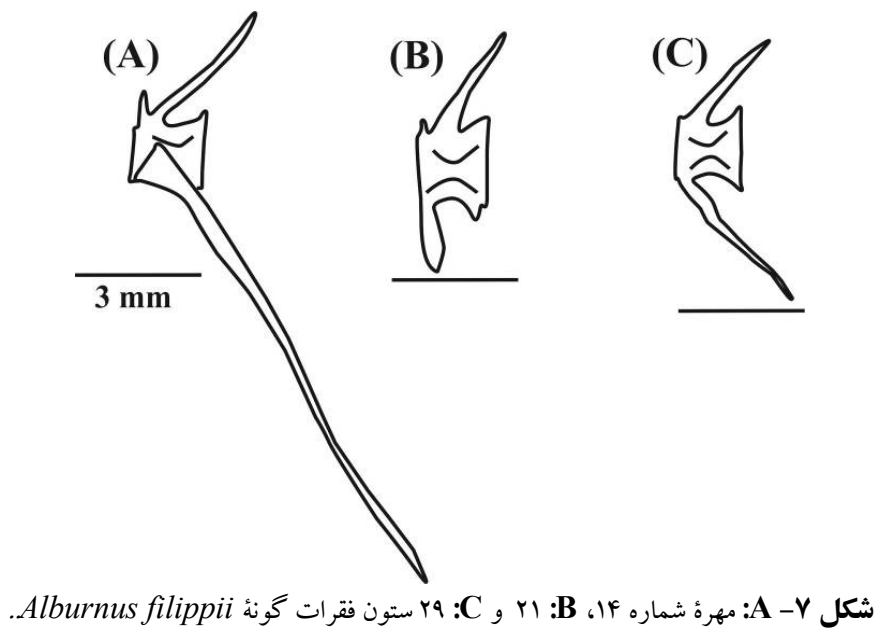

Fig. 7. A: The $14^{\text {th }}, \mathbf{B}: 21^{\text {st }}$ and C: $29^{\text {th }}$ vertebra of Alburnus filippii.

Abbreviations: HPo: Hemal Postzygapophyses; HPr: Hemal Prezygapophyses; NPo: Neural Postzygapophyses; NPr: Neural Prezygapophyses.

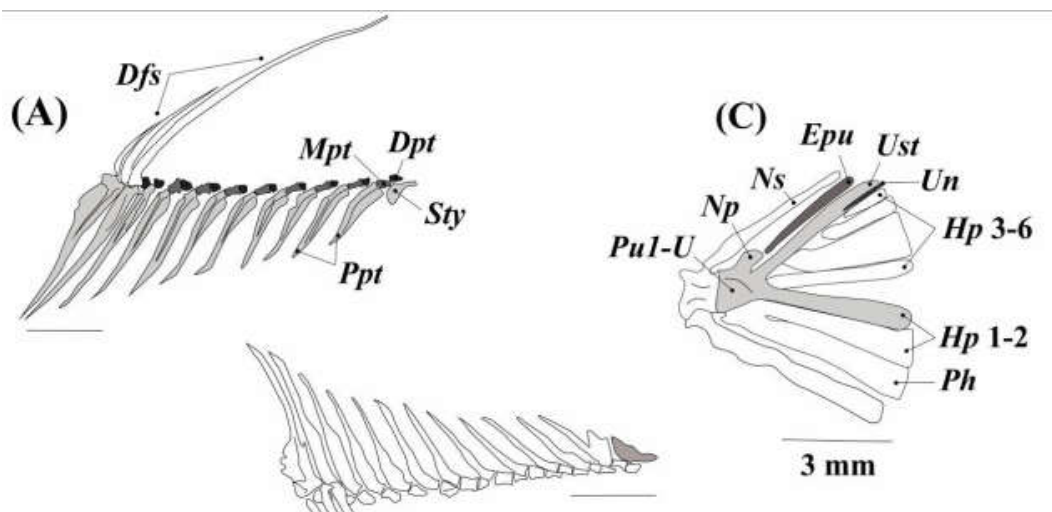

(B)

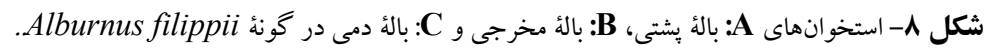

Fig. 8. A: Dorsal, B: anal and C: caudal fins in Alburnus filippii.

Abbreviations: Dfs: Dorsal Fin Spine; Dpt: Distal Petrigiophore; Mpt: Median Petrigiophore; Ppt; Proximal; Epu:epural; Hp1-6:hypural plates 1-6; Ns: neural spine; Np: neural process; Ph: parhypural; Pu1+u: compouned centrum; Ust: pleurostyle; Un: uroneural, Sty: styloid.

دوازده سرى استخوان يُريكيوفور و يكك استخوان استيلوييد Procurrent و مجموعهاى از زوائد استخوانى است كه شامل ينج (Styloid)

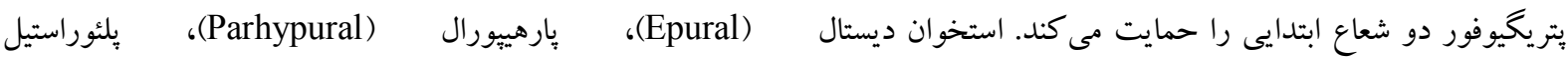

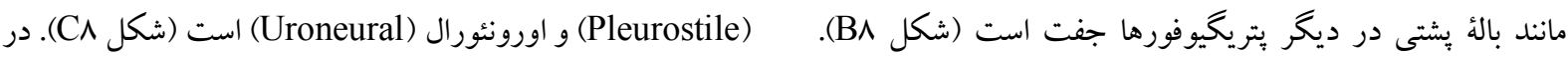
اسكلت بالئ دمى متشكل از آخرين جسم مهره، شعاعهاى اصلى و بخش قدامى -شكمى استخوان بِارهييورال، يكك زائدة زايخك آيوفيز 
A. A. A. mossulensis و A. Ailippii A. chalcoides A. atropatena ،amirkabiri است. در گونهاى Atropatena A. amirkabiri مهرةٌ بالأ دمى دو خار عصبى دارد (Jalili, 2015)، حال آنكه در

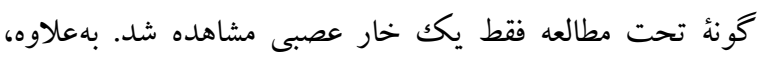

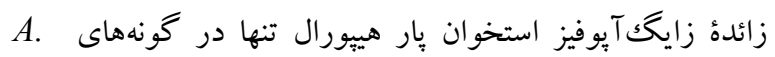
A. atropatena mossulensis تحت مطالعه، تعداد يازده استخوان بتريخيوفور و يكك استخوان

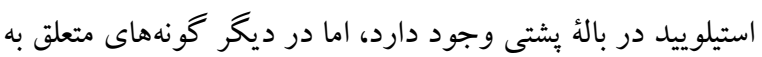
اين جنس نه سرى استخوان بتريخيوفور و يكك استخوان استيلوييد در اين باله مشاهده مىشود (Jalili et al., 2015a, b). تعداد استخوانهاى دورجشمى ازجمله صفاتى است كه در اين جنس بله

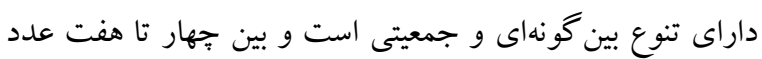
متغير است (Mousavi-Sabet et al., 2014) اما تفاوت مشاهدهده در شكل استخوانهاى دورجشمى در بين گونههاى

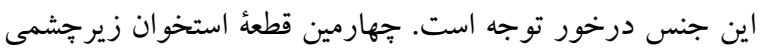

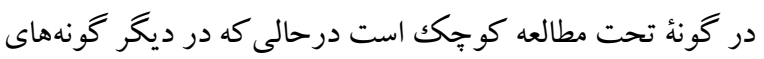

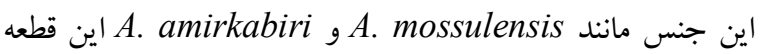
بزرك و بهن است (Jalili et al., 2015a, b). A. filippii در نتيجه گيرى كلى، مى توان بيان داشت كه كون براساس مجموعهاى از ويز گیىهاى استخوانى، شامل تيز بودن زائدة ميانى استخوان فكى، وجود تمايل به بالا در زائدة كورونوئيد

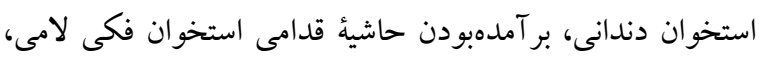

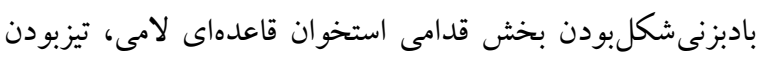

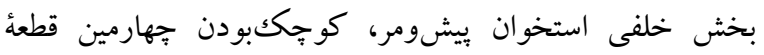

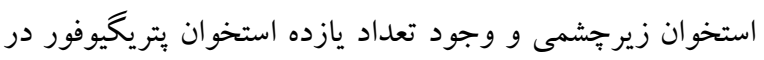

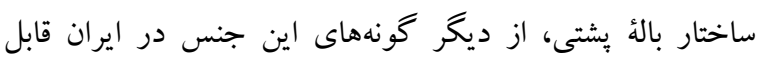

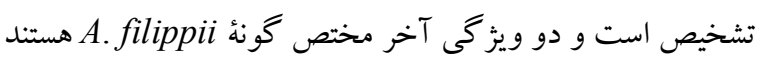

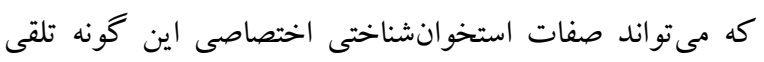

$$
\text { شود. }
$$

سياسگزارى از دانشكاه تهران بهواسطة حمايت مالى اين تحقيق تشكر و

$$
\text { قدردانى مى شود. }
$$

مشاهده مىشود. اين باله شش شعاع Procurrent يشتى و جِهار

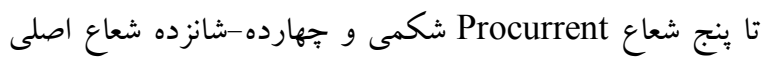
دارد.

\section{بحث}

مقايسٔ ساختار استخوانى ماهى كولى كورا، Ailippii

A. A. mossulensis ،A. amirkabiri A. atropatena ،chalcoides بالا و وِايين، استخوانهاى فككآويز، قاعدهاى لامى، جمجمأ

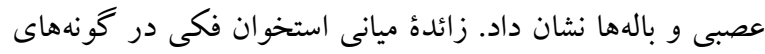
A. chalcoides و A. mossulensis A. filippii A. atropatena, A. amirkabiri درحالى كه در گونهاى كوتاه و بهن است (Jalali, 2013; Jalili et al., 2015 a, b).

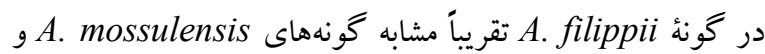
(Jalili et al., 2015) A. amirkabiri A. استخوان دندانى اندكى متمايل به بالا است، اما در گونهاتهای

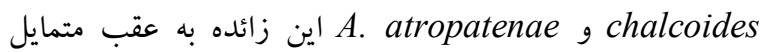
است. حاشئ قدامى استخوان فكى لامى در گونههاى A. filippii A. amirkabiri g (Jalili et al., 2015a) A. mossulensis A. برآمده است، ولى در گونهاى (Jalili et al., 2015) atropatena صاف است (Jalali, 2013). حاشئ خلفى و بشتى استخوان

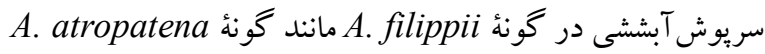

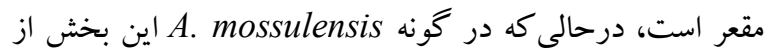
استخوان صاف است. اين صفت در اعضاى متعلق به جنس درنس Alburnus استخوان قاعدهاى لامى نيز تفاوتهايى در بين گونه دهاى اين جنس

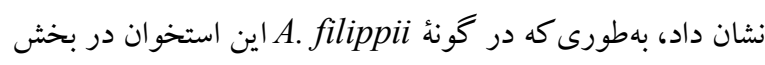
خلفى باريك، و در قسمت قدامى بـهن و بادبزنى شكل مى شود، اما

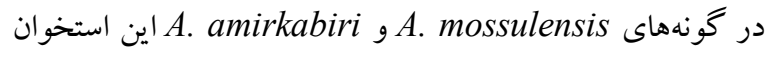
Jalili ) دراز است و تقريباً در تمام طول خود عرض يكسان - et al., 2015

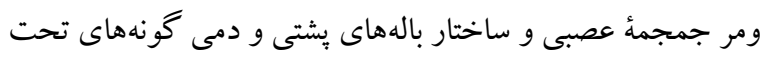

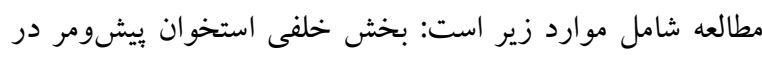




\section{REFERENCES}

Abbasi, K., Valipour, A., Talebi Haghighi, D., Sarpanah, A. and Nezami, Sh. 1999. Atlas of Iranian Fishes, Guilan Inland Waters. - Guilan Fisheries Research Centre, Rasht. 113 pp.

Abdoli, A. and Naderi, M. 2009. Biodiversity of fishes of the southern basin of the Caspian Sea. - Abzian Scientific Publications, Tehran. 243 pp.

Berg, L.S. 1925. Opisanie novogo vida roda Alburnus (Pisces) iz basseina Oz. Urmii [Description of a new species of the genus Alburnus (Pisces) from the basin of Lake Urmia]. - Ezhegodnik Zoologischekogo Instituta Akademii Nauk SSSR, 26: 213-214.

Bogutskaya, N.G., Kucuk, F. and Unlu, E. 2000. Alburnus baliki, a new species of cyprinid fish from the Manavgat River system, Turkey. - Ichthyol. Explor. Freshw. 11: 55-64.

Coad, B.W. 2009c. Alburnus zagrosensis n. sp., a new species of fish from the Zagros Mountains of Iran (Actinopterygii: Cyprinidae). - Zool. Middle. East. 48: 63-70.

Coad, B. 2015. Fresh water fishes of Iran. - Retrieved from http://www.briancoad.com.

Eagderi, S. and Adriaens, D. 2010a. Head morphology of the duckbill eel, Hoplunnis punctata (Regan, 1915; Nettastomatidae: Anguilliformes) in relation to jaw elongation. - Zool. 113: 148-157.

Eagderi, S. and Adriaens D. 2010b. Cephalic morphology of Pythonichthys macrurus (Heterenchelyidae: Anguilliformes): specializations for head-first burrowing. - J. Morphol. 271: 1053-1065.

Helfman, G.S., Collette, B.B., Facey, D.E. and Bowen, B.W. 2009. The diversity of fishes: biology, evolution, and ecology. - Blackwell Publishing. UK, Oxford. 736 pp.

Heckel, J.J. 1843a Abbildungen und beschreibungen der fische syriens nebst einer neuen classification und characteristik sämmtlicher gattungen der cyprinen. Stuttgart 109 pp. In German.

Heckel, J.J. 1843b In: Reisen in europa, asien und afrika, mit besonderer Rücksicht auf die naturwissenschaftlichen Verhältnisse der betreffenden Länder, unternommen in den Jahren 1835 bis 1841 . Russegger, J. (ed), Schweitzerbart'sche Verlagsbuchhandlung. - Stuttgart 1: 991-1099.

Jalali Roshan, S., 2013. Taxonomic study of three species of the genus Alburnus (A.chalcoides, A. atropatenae, A. mossulensis) in Iran using geometric morphometric and osteological methods. - M.Sc. thesis, University of Tehran, Karaj, Iran.

Jalili, P., Eagderi, S. and Azimi, H. and Mousavi-Sabet, $H$. 2015a. Osteological description of the southern king fish, Alburnus mossulensis from Iranian part of the Tigris River drainage. - ABAH Bioflux. 7: 113-121.

Jalili, P., Eagderi, S., Nasri, M. and Mousavi-Sabet, $H$. 2015b. Descriptive osteology of Alburnus amirkabiri (Cypriniformes: Cyprinidae), a newly described species from Namak Lakebasin. Central of Iran. - Bull. Iraq Nat. Hist. Mus. 13: 51-62.

Jalili, P. 2015. Phylogeny of the genus of Iranian Cyprinids using osteological charactrestics. - MSc Thesis, University of Tehran, Iran.

Jouladeh-Roudbar, A. Vatandous S., Eagderi, S., JafariKenari S. and Mousavi-Sabet, H. 2015. Freshwater fishes of Iran; an updated checklist. - AACL Bioflux. 8: 855-909.

Kessler, K.F. 1877. Ryby, vodyashchiesya i vstrechayushchiesya v Aralo-kaspiisko-pontiiskoi ikhtiologicheskoi oblasti [Fishes of the Aral-Caspian-Pontic Ichthyological Region]. - Trudy Aralo-kaspiiskoi ekspeditsii, SanktPeterburg, 4: 1-360, pls. I-VIII.

Kiabi, B.H., Abdoli, A. and Naderi, M. 1999. Status of the fish fauna in the South Caspian Basin of Iran. - Zool. Middle. East. 18: 57-65.

Kottelat, M. and Freyhof, J. 2007. Handbook of European freshwater fishes. - Kottelat, Cornol, Switzerland and Freyhof, Berlin, Germany. 646 pp.

Mohadasi, M., Shabanipour, N. and Eagderi, S. 2013. Habitat-associated morphological divergence in four Shemaya, Alburnus chalcoides (Actinopterygii: Cyprinidae) populations in the southern Caspian Sea using geometric morphometrics analysis. - Int. J. Aquat. Biol. 1: 82-92.

Mohammadian-Kalat, T., Aliabadian, M. and Esmaeili H.R. 2013. Biosystematics of Alburnus in Iran using morphologic and molecular methods. - The First Iranian Conference of Ichthyology, Isfahan University of Technology, $81 \mathrm{pp}$.

Mousavi-Sabet, H., Vatandoust, S., Khataminejad, S., Eagderi, S., Abbasi, K., Nasri, M., Jouladeh, A. and Vasil'eva E.D. 2015. Alburnus amirkabiri (Teleostei), a New Species of Shemaya from the Namak Lake Basin, Iran. - J. Ichthyol. 55: 40-52.

Nasri, M., Keivany, Y. and Dorafshan, S. 2013. Comparative Osteology of Lotaks, Cyprinion kais and C. macrostomum (Cypriniformes, Cyprinidae), from Godarkhosh River, Western Iran. - J. Ichthyol. 53: 455-463.

Rojo, A.L. 1991. Dictionary of Evolutionary Fish Osteology. - CRC Press. 280 pp.

Taylor, W.R. and Van Dyke, G.C. 1985. Revised procedures for staining and clearing small fishes and other vertebrates for bone and cartilage study. - Cybium. 9: 107-119.

How to cite this article:

Nikmehr, N., Eagderi, S. and Jalili, P. 2017. Skeletal structure of Kura bleak, Alburnus filippii (Kessler, 1877), in South Caspian Sea basin. - Nova Biol. Rep. 4: 55-64.

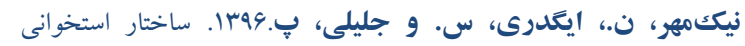

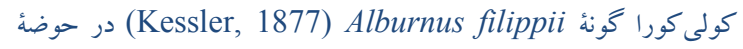
جنوبى درياى خزر. - يافتهاى نوين در علوم زيستى F): 